\title{
Osmanlı Belgelerinde Kürtleri Aramak
}

\author{
Mesut Arslan ${ }^{1}$
}

Received: January 4, 2015 Accepted: January 26, 2015

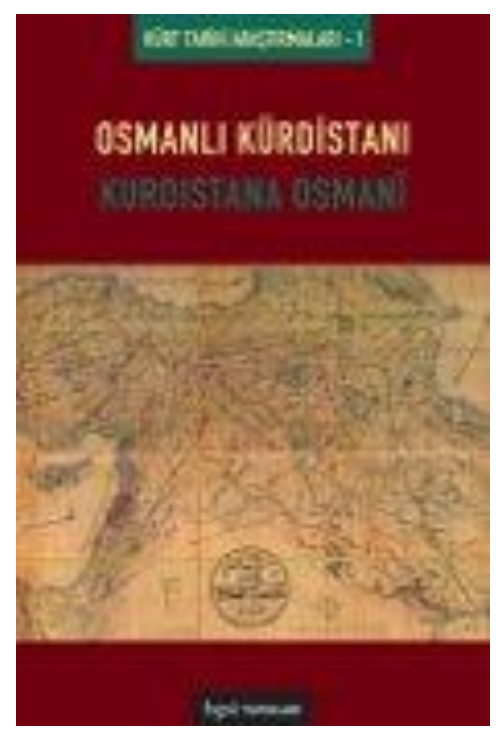

Osmanlı Kürdistanı/Kurdistana Osmanî

Hazırlayan: Kürdoloji Çalışmaları Grubu

Proje Koordinasyonu: Serhat Bozkurt- Alişan Akpınar,

bgst Yayınları, İstanbul, 2011, $354+14$ s.

ISBN: 978-975-6165-45-4

Kürtler, dört yüz yılı aşkın bir süre Osmanlı tebaasıydı. Bu uzun zaman zarfinda Kürtler, Osmanlı nüfusunu oluşturan önemli bir unsur oldu; yurtları da Osmanlı'nın İran ve Rusya sınırını oluşturan önemli bir bölge haline geldi. Bu önemden ötürü Osmanlı arşiv ve kütüphanelerinde Kürtlerle ilgili pek çok belge bulunmaktadır. Bu bilgi ve belgeler meydana çıkarılıp araştırmacıların istifadesine sunuldukça Kürt tarihinin önemli bir evresini oluşturan “Osmanlı Devrinde Kürtler ve Kürdistan Tarihi” de aydınlatılmış olacaktır. Tanıtımını yapacağımız Osmanlı Kürdistanı/Kurdistana Osmanî kitabının amacı da tam olarak budur.

Recommended citation:

Arslan, M. (2016). Osmanlı belgelerinde Kürtleri aramak [Review of the book Osmanlı Kürdistanı/Kurdistana Osmanî by Kürdoloji Çalışmaları Grubu]. International Journal of Kurdish Studies 2 (1), pp. 109 - 111.

\footnotetext{
${ }^{1}$ Research Assistant, Dicle University, PhD Student, Kurdish Language and Culture, Diyarbakır, Turkey, Email: mesutserfiraz@gmail.com
} 
Osmanlı Kürdistanı/Kurdistana Osmanî kitabı, eski adı “Osmanlı Kaynaklarında Kürtler Çalışma Grubu” olan Kürdoloji Çalışmaları Grubu tarafından hazırlandı ve grubun önceki iki kitabı Emîr Bedirhan ve Hînkerê Zimanê Kurdî gibi bgst Yayınları tarafından yayımlandı. Eser, grubun Kürt Tarihi Araştırmaları serisinin ilk kitabını oluşturmaktadır. Osmanlı arşivlerinin tarihî kaynaklarında Kürtlerle ilgili önemli bilgi ve belge bulunduğu ve bu belgeler ortaya çıkarılmadan Kürt tarihinin hakkıyla bilinemeyeceği iddiasıyla yola çıkan grup, bu çalışmada Kürdistan kavramının Osmanlı kaynaklarında nasıl kullanıldığını farklı örneklerle okuyucuya sunarak Cumhuriyetin ilanından bugüne kadar süregelen bir tartışmaya belgelerle katkı sunmaktadir.

Osmanlı Kürdistanı/Kurdistana Osmanî kitabı adı ve içeriğiyle iki dilli bir eserdir. Bunlar Türkçe ve Kürtçedir. Kürdoloji Çalışmaları Grubu, iki dilli hayatın gereğine, anadilde eğitimin Kürtler için önemine ve Kürtçenin bilim dili olmasına binaen böyle bir karar almıştır. Kitapta yer alan altı makalenin hepsi hem Türkçe hem de Kürtçe neşredilmiştir. Ayrıca kitabın sonuna Kürtlerle ilgili Osmanlı belgelerinden örnekler ve Kürdistan vilayetlerinin Osmanlıca orijinal haritaları eklenmiştir. Kitapta kullanılan Osmanlıca belgeler Latin harflerine aktarılmasının yanı sıra günümüz Türkçesine de çevrilmiş, böylece Osmanlıca bilmeyen okuyucular da belgelerin içeriğinden haberdar olabilmektedir.

Kitap, proje koordinatörlerinden Alişan Akpınar'ın önsözüyle başlıyor. Hemen ardından giriş makalesi olarak Namık Kemal Dinç'in "Kadim Anavatandan Bir İnkâr Coğrafyasına: Kürdistan” yazısına yer verilmektedir. Makale 1925'den önce gerek resmî gerek özel belgelerde serbestçe kullanılan Kürdistan kavramının nasıl yasaklandığını, kriminalize edildiğini örneklerle açıklamaktadır.

"Kürdistan Eyaletinin Kurulması ve Osmanlı Devlet Sâlnâmelerinde Kürdistan Eyaleti" makalesi iddia edilenin aksine Osmanlı Devletinde Kürdistan adıyla idarî bir birimin varlığını ispatlıyor ve bu idari birimin sınırlarını devlet salnameleri ve devletin resmî yayın organı Takvim-i Vakayi gazetesi şahitliğiyle gözler önüne sermektedir. Merkeziyetçilik fikrinin etkisiyle uzun isyan ve çatışmaların sonunda 1847 yılında kurulan Kürdistan Eyaleti, Kürdistan'da Yavuz Sultan Selim'den bu yana -yaklaşık 332 yıl- varlıklarını sürdüren Kürt mirliklerinin de sonunu haber vermektedir.

“Coğrafya-yı Osmanî’ de Kürtler ve Kürdistan” adlı makale bize Kürdistan kavramının Osmanlı'da kullanımının ne kadar normal ve yaygın olduğunu göstermektedir. Coğrafya-yı Osmanî, askerî bir okulda coğrafya öğretmeni -aynı zamanda asker- olan Kolağası Ahmet Cemal tarafından idadi okullarının birinci sınıfında okutulmak üzere kaleme alınmış bir coğrafya ders kitabıdır. Kitapta "Kürdistan Kıt'asında Bulunan Vilâyât-1 Şâhâne" başlıklı bir bölüm vardır ve burada Osmanlı Kürdistanı'nın vilayetleri hakkında bilgi verilmektedir. Kitaba göre Osmanlı Kürdistanı altı vilayet ve bir müstakil sancaktan oluşmaktadır. Bunlar: Erzurum, Mamuretülaziz, Diyarbekir, Bitlis, Van, Musul vilayetleri ve müstakil Zor sancağıdır. Bugün için resmî mercilerce basılan bir kitapta Kürdistan coğrafyasına yer verilmesi ve bunun öğrencilere ders olarak okutulması bize imkânsız gibi gelebilir ancak 1895 y1lında durum tam olarak böyledir.

"Lugât-1 Tarihiyye ve Coğrafiyye'de Kürtler ve Kürdistan" yazısı Ahmet Rifat tarafından hazırlanıp 1881-1882 yılları arasında yayımlanan 7 ciltlik Lugât-ı Tarihiyye ve 
Coğrafiyye adlı ansiklopedide yer alan başta Kürd ve Kürdistan olmak üzere Kürtlerle ilgili tüm maddelerin Latin harflerine aktarılmasından oluşmaktadır.

"Kürdistan Malumatı" adlı makalede 1895 yılında kadı naibi Ahmed Fazıl tarafından Hamidiye Alaylarının teşkilatlanmasında ve II. Abdülhamid'in doğu siyasetinde önemli bir role sahip olan Müşir Şakir Paşa’ya sunulmak üzere hazırlanan bir rapor ele alınmıştır. Kürtleri tanıtmak amacıyla hazırlandığı anlaşılan rapor, günümüze kadar sürecek olan Kürt sorunu üzerine rapor yazma geleneğinin ilk örneklerinden olması bakımından da önemlidir.

Osmanl1-Kürt ilişkilerinde dönüm noktası olan olayların başında Çaldıran Savaşı gelir. Bu savaş sonucunda elde ettiği zaferle en büyük rakibi Safevi Devleti’ne karşı üstünlük elde eden Osmanlı, İdris-i Bitlisî aracılığıyla irtibata geçtiği Kürt mirleriyle ittifak kurarak Kürdistan coğrafyasını sınırlarına katar. "Tarih-i Ebu'l-Faruk'ta Kürdistan'ın Fethi” adlı makalede bu süreç son dönem Osmanlı tarihçisi ve aydını Mehmed Murad'ın ya da meşhur adıyla Mizancı Murad'ın kaleminden anlatılmaktadır. 